

\title{
PAISAGEM CULTURAL DAS MISSÕES JESUITICAS GUARANIS: O DESAFIO DE PROMOVER UMA LEITURA PATRIMONIAL DA PAISAGEM
}

\author{
Marcelo Brito \\ Doutor em Gestão Urbana, Pós-Doutorado em Patrimônio, Turismo e Desenvolvimento \\ e Assessor de Relações Internacionais da Presidência do Iphan e Ponto Focal junto à \\ UNESCO para os sítios culturais brasileiros declarados Patrimônio Mundial
}

\section{Ana Clara Giannecchini}

Mestre em Arquitetura e Urbanismo e em Patrimônio e Especialista de Gestão Púbica, arquiteta do Departamento do Patrimônio Material e Fiscalização

\section{RESUMO}

Em 80 anos de atuação no âmbito da política do patrimônio cultural brasileiro, novos desafios cada vez mais complexos põem em xeque a capacidade de resposta do Instituto do Patrimônio Histórico e Artístico Nacional - Iphan. Neste caso, trata-se de compreender o território das missões jesuíticas brasileiras no Estado do Rio Grande do Sul em abordagem sistêmica e multiétnica, respeitando e valorizado as suas referências e tradições culturais, e tendo em vista a sua preservação e o desenvolvimento local. O Projeto de Valorização da Paisagem Cultural e do Parque Histórico Nacional das Missões Jesuíticas dos Guaranis, lançado em agosto de 2014, vem precisamente trabalhar na perspectiva da articulação gradativa de gestores e atores locais e no fomento de ações de desenvolvimento social. Visa ao conhecimento e à caracterização de sua paisagem cultural e à criação de instrumentos de gestão do território do Parque Histórico Nacional das Missões.

Palavras chave: Missões Jesuíticas dos Guaranis, Paisagem Cultural, Parque Histórico 


\section{RESUMEN}

En 80 años de operación de la política del patrimonio cultural brasileño, nuevos retos cada vez más complejos ponen en jeque la capacidad de respuesta del Instituto Histórico Artístico Nacional - IPHAN. En este caso, se trata de entender el territorio de las misiones jesuíticas brasileñas de Río Grande do Sul, en abordaje sistemática y multiétnica, respetando y valorando sus referencias culturales y tradiciones, y con miras a su conservación y desarrollo local. El Proyecto de Valorización del Paisaje Cultural y del Parque Histórico Nacional de Misiones Jesuíticas de los Guaranies, lanzado en agosto de 2014, va precisamente trabajar hacia la articulación progresiva de los gestores y actores locales y la promoción de acciones de desarrollo social. Visa al conocimiento y caracterización de su paisaje cultural y a la creación de instrumentos de gestión del territorio del Parque Histórico Nacional de Misiones.

Palabras clave: Misiones Jesuíticas, Paisaje Cultural, Parque Histórico Nacional

\section{ABSTRACT}

In 80 years of operation of the policy of the Brazilian cultural heritage, new challenges of increasing complexity call into question the responsiveness of the National Historical and Artistic Heritage Institute - Iphan. In this case, the question is to understand the territory of Brazilian Jesuit Missions in Rio Grande do Sul through a systematic and multi-ethnic approach, respecting and valuing their cultural references and traditions, with a view to their preservation and local development. The Project of Valorization of the Cultural Landscape and the National Historic Park of Jesuit Missions of the Guarani, launched in August 2014, precisely works towards the gradual articulation of managers and local stakeholders and the promotion of social development actions. Aims the knowledge and the characterization of its cultural landscape and the creation of land management instruments for the National Historic Park of Jesuit Missions.

Key words: Jesuit missions of Guarani, Cultural Landscape, National Historical Park 


\section{INTRODUÇÃO}

A chancela brasileira da Paisagem Cultural, criada pelo Instituto do Patrimônio Histórico e Artístico Nacional-IPHAN em 2009, enfocou o reconhecimento do poder público em uma mudança substancial na visão sobre o patrimônio cultural, alterando a escala de abordagem e ampliando a lente temática de observação. Instrumentos e experiências que possam traduzir essa perspectiva ainda são escassos no panorama brasileiro. O delicado processo de articulação e mobilização dos atores e parceiros atuantes na paisagem implica em requisitos específicos e demanda estratégias apropriadas, que se diferenciam daquelas utilizadas comumente em bens isolados ou de menor complexidade.

Em gestação desde 2005, o Projeto de Valorização da Paisagem Cultural e do Parque Histórico Nacional das Missões Jesuíticas dos Guaranis ${ }^{1}$ vem, precisamente, trabalhar na perspectiva da articulação gradativa e no fomento de ações locais. Visa, em seu princípio, ao conhecimento da paisagem cultural das Missões Jesuíticas Guarani e ao desenvolvimento de instrumentos de gestão que auxiliem no processo de instalação de um Parque Histórico Nacional no local. O Parque deverá se configurar como instrumento que preconiza o valor do território como patrimônio local, nacional e mundial e que promove a diversidade sociocultural e ambiental, assim como o potencial de ferramenta indutora do desenvolvimento regional.

O formato de Projeto de Cooperação Técnica Internacional permite o aporte de novos conhecimentos e experiências internacionais no tema, qualificando a construção do instrumento nacional. O IPHAN vem trabalhando com projetos de cooperação internacional desde os primórdios do Programa Monumenta, em 1999, um programa de peso voltado para as cidades históricas, financiado pelo BID, carreado pelo Ministério da Cultura e pelo IPHAN e com aporte técnico da Organização das Nações Unidas para a Educação, a Ciência e a Cultura - UNESCO, composto de uma multiplicidade de ações de preservação, educação e fomento, que pretendeu promover a preservação associada ao desenvolvimento.

O Projeto Missões corresponde assim a um compromisso entre o Instituto do Patrimônio Histórico e Artístico Nacional (IPHAN, enquanto instituição executora), a Organização das Nações Unidas para a Educação, a Ciência e a Cultura (UNESCO, enquanto Agência de

1 De ora em diante denominado Projeto Missões. 
Cooperação Internacional para assistência técnica) e a Agência Brasileira de Cooperação ( $A B C$, enquanto representante do Governo Brasileiro). Com o seu desenvolvimento nos próximos 36 meses $^{2}$, espera-se, para além de um conhecimento sistematizado sobre o território e de instrumentos criados, a criação de novas alianças e a atração de investimentos públicos e privados capazes de propiciar a instalação e o funcionamento de equipamentos do Parque.

\section{ANTECEDENTES E HISTÓRICO}

Quase 80 anos de atuação no âmbito da política patrimonial, novos desafios cada vez mais complexos põem em xeque a capacidade de resposta de uma instituição, da qual se exige um permanente reinventar-se.

Trata-se do Instituto do Patrimônio Histórico e Artístico Nacional - Iphan, instituição federal responsável pela política de preservação e salvaguarda do patrimônio cultural brasileiro e, neste caso, por promover uma abordagem sobre os sítios missioneiros localizados no noroeste do estado do Rio Grande do Sul que permitam entendê-los e geri-los a partir de sua concepção original: os 30 povos das Missões, em sua estrutura sistêmica, com seu sistema reducional pautado na especialidade e complementaridade enquanto estratégia de ocupação territorial.

A gênese desse salto se expressa com a criação do Parque Histórico Nacional das Missões - PHNM, na última revisão da estrutura organizacional do Instituto, ocorrida em 2009, mediante o Decreto no 6844, quando é estabelecido e aplicado para o caso das Missões.

Esse sistema, no Brasil, tratado historicamente a partir dos sítios missioneiros remanescentes de São Miguel Arcanjo, São João Batista, São Nicolau e São Lourenço Mártir, é, contudo, considerado pelo Iphan, na prática, como um conjunto de bens culturais isolados, testemunhos arqueológicos daquele sistema reducional que sobreviveram ao tempo, deixando marcas que resistiram tanto à presença como à ausência humana, a partir de ações de proteção e conservação providas pelo Instituto e que se realiza desde 1938.

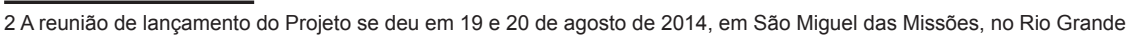
do Sul.
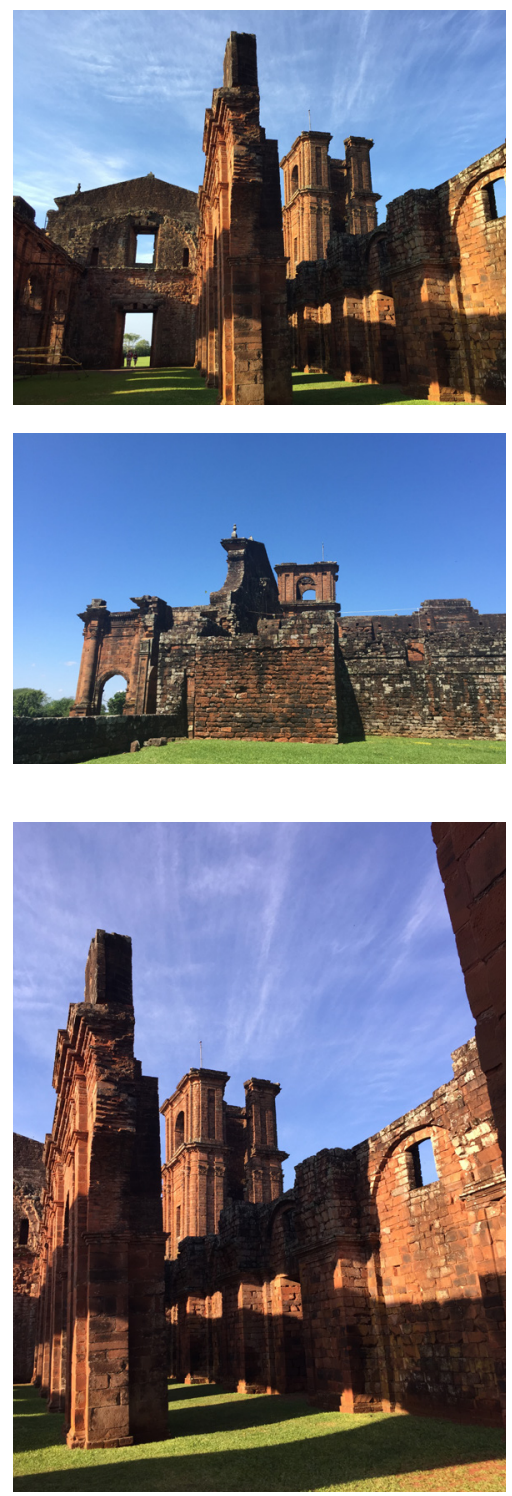

Ruínas de São Miguel Arcanjo. Foto: Rafael Volochen 


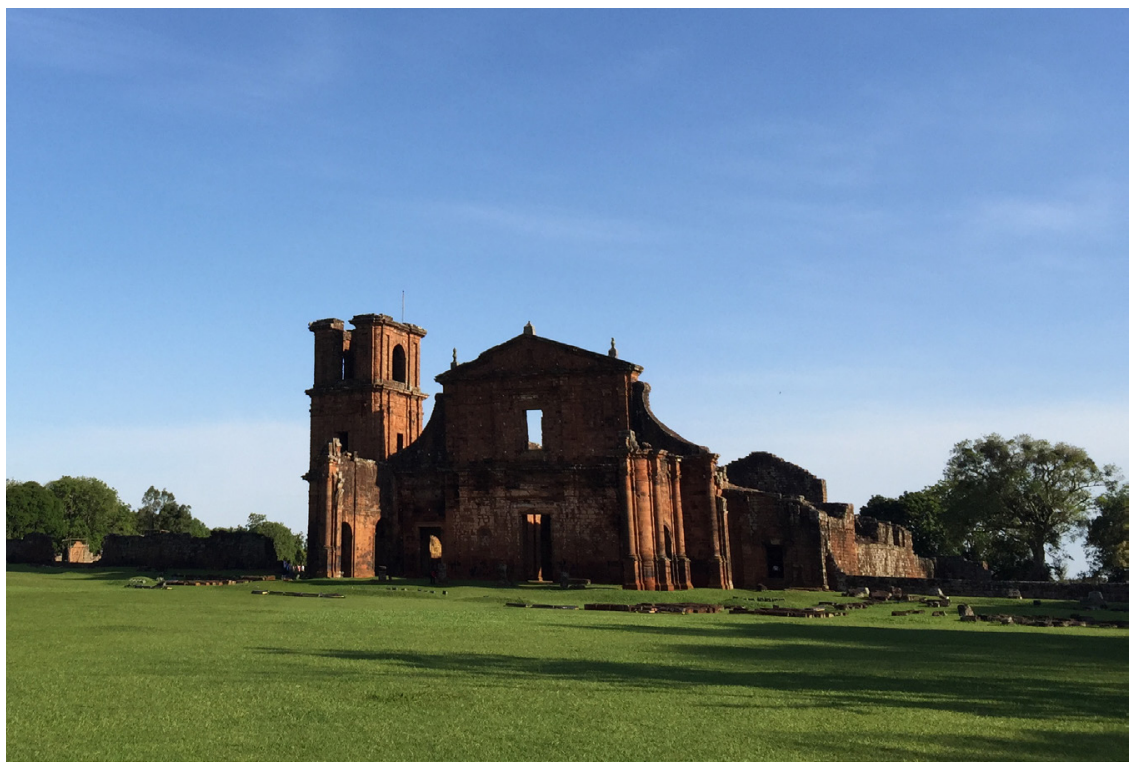

No entanto, o deslocamento conceitual que se opõe a essa prática, que insistiu em atuar sobre os fragmentos disponíveis como um quebra-cabeças ainda por completar, realizase com as interações que são produzidas a partir de 2004 entre o Iphan e o Instituto Andaluz do Patrimônio - IAPH, instituição espanhola vinculada ao Governo da Andaluzia. Essa instituição vinha desenvolvendo à época estudos sobre território e patrimônio e sua relação com as paisagens andaluzas (2003), assim como sobre metodologia de diagnóstico e avaliação para tratamento da conservação de edifícios históricos (2003), pesquisa, documentação e intervenção em antropologia e patrimônio (2003), sistemas de informação do patrimônio arqueológico (2003), indicadores para avaliação do estado de conservação de cidades históricas (1999) e reflexões e debates sobre a teoria e a prática da conservação arqueológica (1994), entre outros.

Dessa articulação produzida, foi estabelecido um acordo de cooperação técnica, em 2005, entre os dois Institutos que tomou como base central para atuação o caso das Missões, com o objetivo de desenvolver um guia de paisagem cultural para promover o desenvolvimento sustentável do território das Missões Jesuíticas Guaranis no Brasil, proporcionando um 
interessante debate entre suas áreas técnicas, especialmente quando da realização do workshop sobre sistemas de informação e paisagem cultural, em Brasília, em 2008. Das iniciativas produzidas em função dessa cooperação bilateral, são desenvolvidos, particularmente, um inventário dos recursos arquitetônicos da região, um estudo sobre o potencial de desenvolvimento turístico e estratégias de atuação para as Missões no Brasil, a realização de prospecções geofísicas mediante sondagens para orientar intervenções arqueológicas em São Miguel das Missões, um estudo sobre a coleção do Museu das Missões, um guia turístico-cultural das Missões (não concluído) e um inventário de referências culturais para a valorização do mundo cultural Guarani, este último, com o apoio da Agência Espanhola de Cooperação Internacional para o Desenvolvimento - AECID e a participação do CTI - Centro de Trabalho Indigenista, associação não governamental, constituída por profissionais atuantes no campo da gestão ambiental e no fortalecimento das práticas socioculturais de sociedades indígenas.

Ao longo desse período, cabe registrar importantes contribuições dadas ao tema, como a do arquiteto paisagista Carlos Fernando de MOURA DELPHIM, do Iphan, em 2009, ao enfatizar a necessidade de que não cabia mais considerar, por exemplo, São Miguel Arcanjo - sítio declarado Patrimônio Mundial, pela UNESCO, em 1983 - "como um sítio avulso, mas como parte indissociável de um contexto muito mais amplo que é todo o território das Missões". Neste sentido, verificava-se que "...a unidade territorial deveria ter prevalência sobre o conceito de sítio", que "o conceito de paisagem é comumente confundido com o de sítio" e que "Sítio é um lugar, paisagem, um sistema".

Diante dos intercâmbios produzidos, do acesso à informação especializada no campo da paisagem, da troca de experiências nas diversas matérias relacionadas, o desafio de promover uma leitura patrimonial da paisagem, para o caso das Missões, foi se delineando e se consolidando a partir de 2012, quando o conceito de paisagem ganha para o Brasil, e em particular, para o Iphan, outra dimensão ao ser declarada Patrimônio Mundial a paisagem cultural do Rio de Janeiro, na 36a Sessão do Comitê do Patrimônio Mundial realizada em São Petersburgo, na Rússia.

Legitimado por esse processo crescente de incorporação conceitual do conceito de paisagem, o Iphan passa a desenvolver um novo projeto, incorporando a experiência anteriormente acumulada para dotar-se das condições operacionais adequadas para a sua realização. 


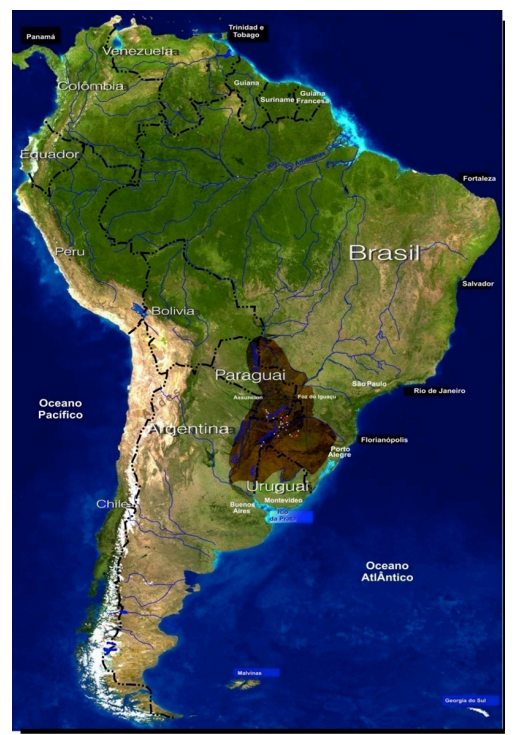

Território de ocupação jesuíta no Brasil, Uruguai, Paraguai e Argentina

Os 30 povos de missões jesuíticas fundados nesses países

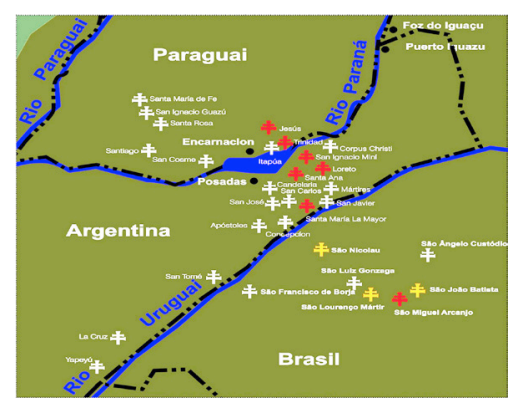

Pautado na abordagem do território como Paisagem Cultural, buscando uma interação entre os processos culturais e o meio ambiente, assim como a valorização dos sítios arqueológicos pela compreensão do sistema reducional, do qual fazem parte, é proposta a implementação do Parque Histórico Nacional das Missões. Criado regimentalmente na estrutura organizacional do Instituto, carece de diretrizes e princípios que orientem uma política governamental baseada na perspectiva de tornar o seu patrimônio um ativo para apoiar o desenvolvimento sociocultural e econômico da região, projetando e estabelecendo perspectivas para o seu desenvolvimento, construindo uma ponte entre passado, presente e futuro. Pretende-se, portanto que a figura de gestão "Parque Histórico Nacional" seja uma alternativa para gerir esses territórios de relevante interesse cultural.

\section{O PROJETO}

O empreendimento missioneiro se expandiu territorialmente para muito além das ruínas de São Miguel Arcanjo ou das ruínas dos remanescentes das outras três missões tombadas no Brasil: São Nicolau, São João Batista e São Lourenço Mártir. A iniciativa reducional alcançou a área equivalente à quase totalidade do Estado do Rio Grande do Sul, parte de Santa Catarina e do Paraná, boa parte do Uruguai e do Paraguai, e parcela do nordeste da Argentina.

Hoje, a zona de influência no Brasil abrange 26 municípios, alguns com ruínas expostas, outros com remanescentes ainda encobertos por novas cidades e outros mantendo as práticas e os modos de vida que caracterizam a herança cultural relacionada às missões jesuíticas. A etnia M'bya Guarani tem nesses mesmos espaços referências materiais e simbólicas que extrapolam a aldeia Tekoá Ko'ënjú, localizada no município de São Miguel das Missões.

É esse o território sobre o qual se direciona o Projeto Missões, desenhado para se desenvolver em duas etapas principais, uma de caracterização da paisagem e delimitação do Parque Histórico Nacional das Missões - PHNM, e outra de elaboração do plano de funcionamento e desenvolvimento do Parque, incluindo projetos para equipamentos e programas de atuação. 
$\mathrm{Na}$ primeira etapa, prevê-se a sistematização do conhecimento dos Sete Povos das Missões - que incidem no território brasileiro - , considerando os estudos já realizados ${ }^{3} \mathrm{e}$ as lacunas existentes, particularmente aquelas referentes a leituras históricas e paisagísticas baseadas na visão de outros grupos étnicos até o momento pouco considerados, como os Guaranis. Esse conhecimento inclui o documental, o iconográfico, o fotográfico, o cartográfico e o de acervo móvel. Pretende-se disponibilizar essa informação e facilitar seu acesso aos pesquisadores e gestores do PHNM. A caracterização da paisagem deve-se dar pelo mapeamento do território e sua exploração in loco, com a setorização da paisagem e delimitação do Parque, sempre promovendo a participação das entidades parceiras e reuniões de debate e compartilhamento das propostas desenvolvidas.

Na segunda etapa do Projeto, serão definidas as diretrizes de preservação e gestão do Parque e concebido um desenho institucional, incluindo definição de uma estrutura de governança, um modelo de gestão, estratégias de ação, formas de cooperação e instrumentos de implementação. Pretende-se ainda elaborar um plano estratégico para o PHNM e definir indicadores de monitoramento e avaliação da proposta idealizada para o Parque. O projeto foi pensado para criar condições bastante consistentes para o início da operação do Parque. Assim, foram previstos também recursos para o desenvolvimento de alguns projetos prioritários como roteiros interpretativos, sinalização indicativa e interpretativa, conservação dos vestígios arqueológicos, estruturas de apoio ao Parque, iluminação e acessibilidade, programa de ações educativas, incluindo capacitação e promoção do PHNM.

Enquanto projeto de desenvolvimento local, a iniciativa pressupõe o envolvimento e a participação de agentes governamentais e não governamentais que atuam na região, desde o princípio. Por esse motivo, foi criada uma estrutura de governança, para além de sua Direção Nacional, composta de quatro níveis: Coordenação Nacional, Comitê Gestor, Comissão Executiva e Grupo Assessor.

3 Destacam-se, entre outros: os Inventários da estatuária missioneira; os Inventários realizados pelo IPHAE e pelo IPHAN, incluindo o Inventário Nacional de Referências Culturais (INRC) da Comunidade M'byá Guarani em São Miguel Arcanjo e outros do patrimônio imaterial; os inventários da Universidade Regional Integrada do Alto Uruguai e das Missões (URI) nos municípios, que inclui cartografia (Núcleo de Geoprocessamento da URI); o banco de dados de sítios arqueológicos do IPHAN; os trabalhos acadêmicos da UNIPAMPA e outras universidades da região; os estudos de tombamento de São Nicolau, São Borja, Sítio Histórico de Santo Ângelo pelo IPHAE; o Observatório Missioneiro de Atividades Criativas e Culturais - OmiCult; o Projeto em parceria UNIPAMPA + Universidade Federal de Pernambuco (UFPE) de Mapeamento de instituições Culturais da Região das Missões; a ação fruto da parceria IPHAN - Centro Regional para a Salvaguarda do Patrimônio Cultural Imaterial da América Latina (CRESPIAL) da Cartografia Cultural Guarani.

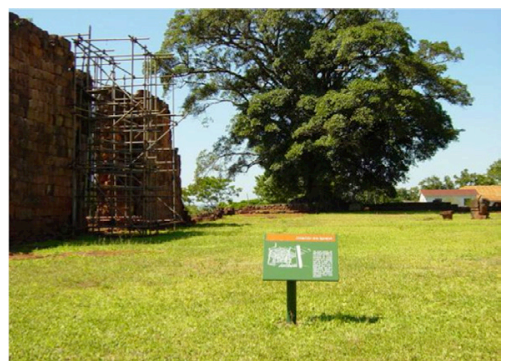

Ruínas de São Nicolau

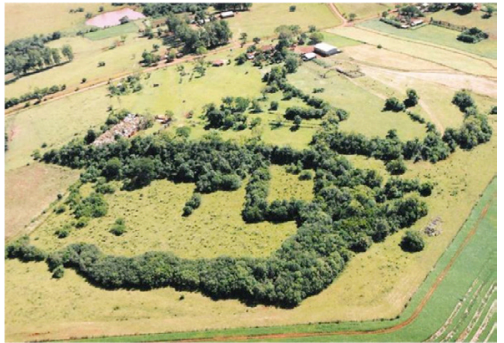

Ruínas de São João Batista

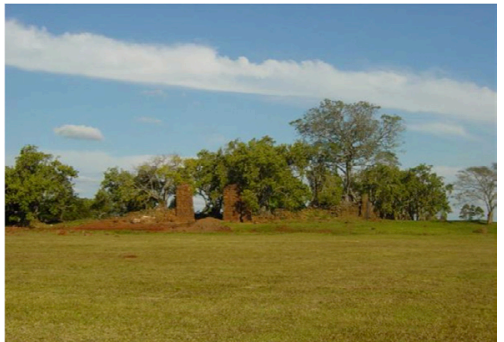

Ruínas de São Lourenço Mártir 
Mapa de abrangência atual do território de missões no Brasil, incluindo 26 municípios

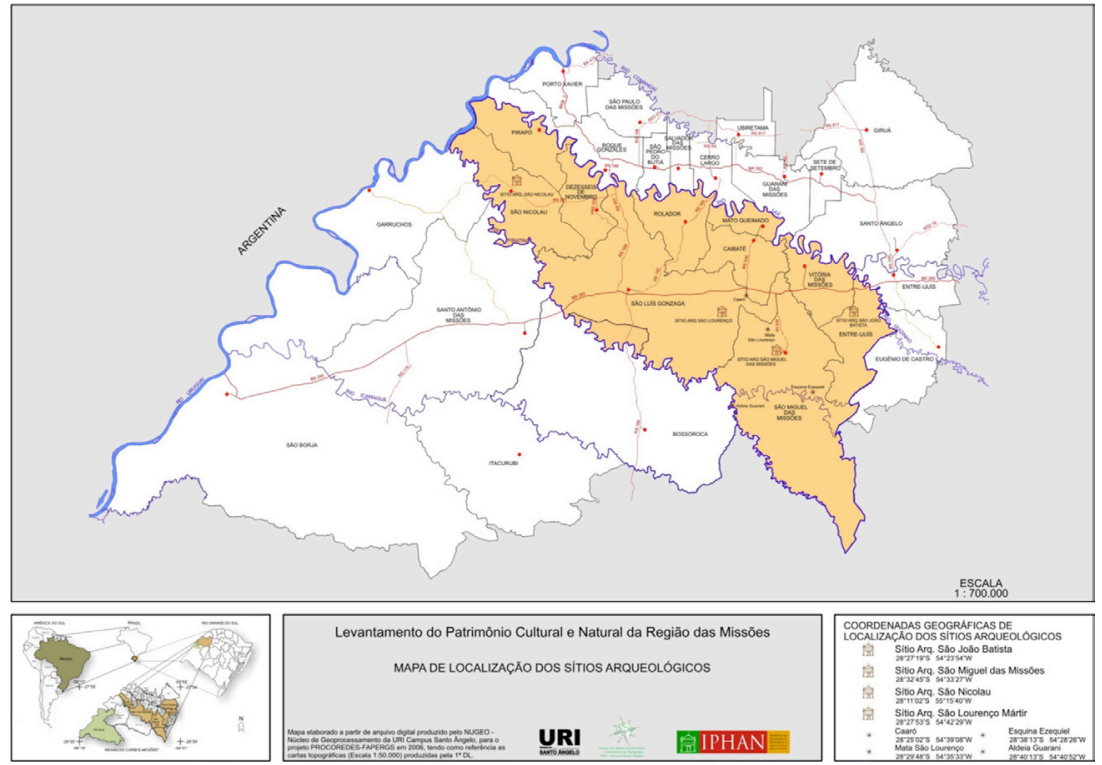

A Coordenação Nacional, na figura de seu coordenador, é indicada pelo Presidente do IPHAN, é aquele que ordena as despesas e representa o projeto perante a $A B C$ e a UNESCO, e coordena o planejamento, a execução e a avaliação do projeto, assim como as articulações com os parceiros para o desenvolvimento dos trabalhos. O Coordenador convoca as demais instâncias a subsidiá-lo na gestão do Projeto.

O Comitê Gestor possui a função de supervisionar e promover a coordenação integrada do Projeto, envolvendo os representantes do IPHAN - incluindo a Superintendência do IPHAN no Rio Grande do Sul, os Departamentos de Patrimônio Material e Fiscalização (DEPAM), de Patrimônio Imaterial (DPI) e de Articulação e Fomento (DAF), e a Assessoria de Relações Internacionais (ARIN) - e os representantes da UNESCO. Este desenho reflete a intenção de produzir inovações nacionais ao se criar uma figura de gestão que possa ser replicada em outras situações similares no país. O Comitê deve buscar facilitar interlocução com as instituições signatárias, discutir com o Coordenador as prioridades de implementação e o decurso dos trabalhos. 


\begin{tabular}{|c|c|c|}
\hline $\begin{array}{l}\text { INSTÂNCIAS DE } \\
\text { GOVERNANÇA }\end{array}$ & COMPOSIÇÃO & FUNÇÖES \\
\hline Diretor Nacional & Presidência do IPHAN & $\begin{array}{l}\text { Representar o órgão ou entidade executora nacional perante a ABC, a } \\
\text { UNESCO e os órgãos de controle, responsabilizando-se pelas atividades } \\
\text { desenvolvidas no âmbito do projeto; } \\
\text { Ordenar as despesas; } \\
\text { Designar e exonerar o Coordenador do projeto; } \\
\text { Aprovar os relatórios de progresso elaborados pelo Coordenador e } \\
\text { encaminhá-los à ABC e à UNESCO. }\end{array}$ \\
\hline $\begin{array}{l}\text { Coordenador } \\
\text { Nacional }\end{array}$ & $\begin{array}{l}\text { Presidência do IPHAN ou seu representante indicado } \\
\text { (Superintendente do IPHAN no Rio Grande do Sul) }\end{array}$ & $\begin{array}{l}\text { Substituir o Diretor Nacional do Projeto em suas ausências e impedimentos; } \\
\text { Auxiliar o Diretor Nacional na Gestão do Projeto; } \\
\text { Ordenar as despesas do projeto, a partir de designação do Diretor Nacional; } \\
\text { Coordenar a elaboração e a execução dos planos de trabalho do projeto.; } \\
\text { Coordenar a elaboração de Acordos de Cooperação ou similares com } \\
\text { parceiros do Projeto, conforme a necessidade; } \\
\text { Zelar pelo cumprimento do cronograma de implementação do projeto; } \\
\text { Coordenar a elaboração de relatórios de progresso com informaçôes } \\
\text { técnicas e administrativas e financeiras do projeto; } \\
\text { Assegurar a manutenção dos arquivos organizados com a documentação do } \\
\text { projeto; } \\
\text { Promover articulações com outras instituições para o desenvolvimento do } \\
\text { projeto; } \\
\text { Convocar as reuniões do Comitê Gestor, da Comissão Executiva e a } \\
\text { assessoria do Grupo Assessor para subsidiá-lo na gestão do projeto. }\end{array}$ \\
\hline Comitê Gestor & $\begin{array}{l}\text { Pelo IPHAN: } \\
\text { Chefe do PHNM ou seu representante } \\
\text { Superintendente do Iphan no Rio Grande do Sul ou } \\
\text { seu representante } \\
\text { Diretor do Departamento de Patrimônio Material e } \\
\text { Fiscalização ou seu representante ou seu } \\
\text { representante } \\
\text { Diretor do Departamento de Patrimônio Imaterial ou } \\
\text { seu representante } \\
\text { Diretor do Departamento de Articulação e Fomento ou } \\
\text { seu representante } \\
\text { Assessor de Relaçōes Internacionais ou seu } \\
\text { representante } \\
\text { Pela UNESco, a Coordenadora de Cultura ou seu } \\
\text { representante }\end{array}$ & $\begin{array}{l}\text { Coordenação e supervisão geral: } \\
\text { Facilitar a interlocuçăo entre as instituiçães signatárias do projeto, buscando } \\
\text { o seu aprimoramento continuo. } \\
\text { Assistir a Coordenação Nacional na definição de prioridades de } \\
\text { implementação. } \\
\text { Avaliar os planos anuais de trabalho do projeto. } \\
\text { Acompanhar os relatórios de progresso do projeto. }\end{array}$ \\
\hline $\begin{array}{l}\text { Comissão } \\
\text { Executiva }\end{array}$ & $\begin{array}{l}\text { Chefe do PHNM } \\
\text { Representantes: } \\
\text { Guarani } \\
\text { Prefeitura de Santo Ângelo } \\
\text { Prefeitura de São Migue } \\
\text { Prefeitura de São Luiz Gonzaga } \\
\text { Prefeitura de São Nicolau } \\
\text { Prefeitura de Entre-ljuís } \\
\text { Prefeitura de São Borja } \\
\text { Associação dos Municípios das Missões } \\
\text { Governo do Estado, pelo Instituto do Patrimônio } \\
\text { Histórico e Artistico Estadual (IPHAE) } \\
\text { Fundação dos Municipios das Missões } \\
\text { Associação dos Amigos das Missőes } \\
\text { Defesa Civil do Patrimônio Histórico (DEFENDER) }\end{array}$ & 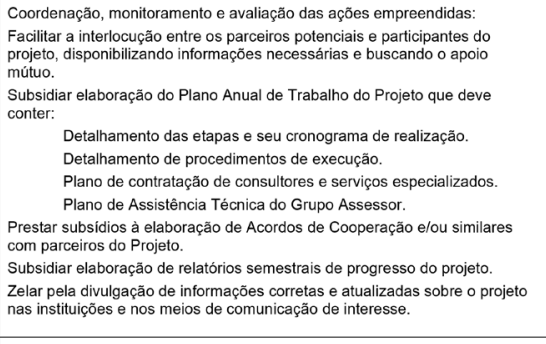 \\
\hline Grupo Assessor & $\begin{array}{l}\text { Representantes: } \\
\text { Universidade Federal do Pampa (UNIPAMPA) } \\
\text { Instituto Andaluz do Patrimônio Histórico (IAPH) } \\
\text { UNESCO Brasil }\end{array}$ & $\begin{array}{l}\text { Assistências técnica especializada em áreas/temas de interesse para a } \\
\text { implementação do PHNM }\end{array}$ \\
\hline
\end{tabular}

Tabela 1: Quadro das instâncias de governança do Projeto Missões 
Tabela 2: Quadro preliminar de entidades parceiras, enumeradas na reunião de lançamento do Projeto
1 Departamento do Meio Ambiente da Associação de Municípios das Missões

2 Associação Rio-Grandense de Empreendimentos de Assistência Técnica e Extensão

Rural(EMATER/RS-Ascar) - atuação estadual

Movimento dos Atingidos pelas Barragens (MAB)

Colônias de pescadores da região

5 Fundação Zoobotânica e Fundação Estadual de Proteção Ambiental (FEPAM), ambos da

Secretaria Estadual do Meio Ambiente (SEMA) - geoprocessamento

6 Fundação Metropolitana de Planejamento (METROPLAN) - vinculada à Secretaria de Obras do Estado

7 Fundação Nacional do Índio (FUNAI)

8 Serviço Brasileiro de Apoio às Micro e Pequenas Empresas (SEBRAE) - artesanato

9 Federação dos Hotéis, Bares, Restaurantes e Similares - Representação Regional de Missões

10 Empresas de logística

11 Associação Regional de Guias de Turismo das Missões

12 Sociedade de Arqueologia Brasileira (SAB)

13 Instituto Federal Farroupilha - Campus São Borja e novo campus de Santo Ângelo

14 Sistema Estadual de Museus

15 Centro de Trabalho Indigenista (CTI) e Comissão de Terras

16 Conselho Estadual dos Povos Indígenas

17 Universidade Federal da Fronteira Sul (UFFS) - Campus Cerro Largo

18 Universidade Federal do Rio Grande do Sul (UFRGS)

19 Pontifícia Universidade Católica (PUC-RS)

20 Universidad

21 Universidade Regional do Noroeste do Estado do Rio Grande do Sul (Unijuí)

22 Universidade Federal de Santa Maria (UFSM)

23 Secretaria Estadual de Educação

24 Universidade Federal de Pelotas (UFPEL)

25 Ministério do Turismo e EMBRATUR

26 Federação de Associações dos Municípios do Rio Grande do Sul

27 Confederação Nacional dos Municípios (CNM)

28 Organização das Cidades Patrimônio Mundial

29 Associação Brasileira das Cidades Históricas

30 Associação Nacional de História - Seção do Rio Grande do Sul 
Objetivo 1 - Produzir conhecimento acerca das Missões Jesuíticas dos Guaranis, com vistas à caracterização de sua paisagem e à sua proteção, por meio da identific ação, reunião e sistematização de fontes documentais diversas

Resultado 1.1 - Iconografia, fotografias artísticas e documentais, bens móveis missioneiros e cartografia geográfica e urbana sobre os Sete Povos das Missões Jesuíticas dos Guaranis identificadas, classificadas, reunidas e disponibilizadas aos pesquisadores e gestores do Parque Histórico Nacional das Missões

Atividade 1.1.1 - Pesquisar e identificar em bibliotecas, fundos de museus e arquivos, cartografia geográfica e urbana de interesse para a geração de conhecimento e gestão do Parque Histórico Nacional das Missões.

\begin{tabular}{|l}
\hline Atividade 1.1.2 - Pesquisar e identificar iconografia ilustrativa dos Sete Povos das Missões, em especial as produzidas por viajantes. \\
\hline Aividde
\end{tabular}

Atividade 1.1.3 - Definir conjunto prioritário da iconografia, fotografia e cartografia para compor o acervo documental dos Sete Povos das Missões Jesuiticas dos Guaranis

Atividade 1.1.4 - Confimar a localizaçāo e classificar os bens móveis missioneiros - principalmente as imagens sacras em madeira e pedra - dispersos pelo território, segundo os parâmetros de temporalidade, procedência, material, etc.

Atividade 1.1.5 - Conceber Guia Geral de Fontes Iconográficas, Fotográficas e Cartográficas acerca dos Sete Povos das Missões.

Resultado 1.2 - Paisagem Cultural das Missões caracterizada, delimitada e diretrizes de gestão e preservação estabelecidas

Atividade 1.2.1 - Levantamento das instituições $e$ atores $e$ instrumentos de gestão que atuam e incidem sobre a área;

Atividade 1.2.2 - Analisar o conjunto documental identificado e desenvolver histórico sobre a ocupaçăo do território com vistas a sua caracterização:

Atividade 1.2.3 - Realizar mapeamento atual do território, com base na documentação coletada, bem como na exploração in loco.

Atividade 1.2.4 - Caracterizar o território das Missőes, seus distintos setores e patrimônio associado através das variáveis físicas e antropológicas, para produzir o mapa da paisagem da regiäo:

Atividade 1.2.5 - Propor e debater a delimitação do Parque Histórico Nacional das Missões - PHNM;

Atividade 1.2.6 - Identificar, destacar e aprofundar o conhecimento sobre paisagens de interesse, que integram o PHNM, para a definição de diretrizes de gestão e preservação para estas áreas.

Atividade 1.2.7 - Promover reuniões de compartilhamento e apropriação dos resultados acerca da leitura e caracterização da paisagem entre as áreas
gestâo e preservacão para estas areas.

Atividade 1.2.7 - Promover reuniós de compart
técnicas do IPHAN e gestores municipais da área

Objetivo 2 - Conceber e testar instrumentos e projetos estruturantes, tanto do ponto de vista institucional quanto físico, necessários para a

implantação do PHNM.

Resultado 2.1 - Estrutura institucional e planejamento estratégico do Parque Histórico Nacional das Missões definidos

Atividade 2.1.1 - Consolidar os estudos de caracterização e diretrizes de preservação e gestão do PHNM no Guia da Paisagem das Missões, como instrumento de gestão do Parque.

Atividade 2.1.2 - Conceber desenho institucional e jurídico do PHNM, incluindo definição de estrutura de governança, modelo de gestão, estratégias, formas de cooperação, cronogramas e instrumentos de implementação.

Atividade 2.1.3 - Realizar estudos para subsidiar a elaboração de planejamento estratégico do PHNM, contemplando o envolvimento das diferentes comunidades beneficiadas.

Atividade 2.1.4 - Realizar estudos para subsidiar a elaboração de sistema de indicadores de avaliação das ações do Parque que serão objeto de

Atividade 2.1.4 - Realizar estudos para subsidiar a elaboraçăo de sistema ce indicadores ce aval
validação junto aos gestores municipais quanto aos aspectos atinentes às suas territorialidades.

Resultado 2.2 - Projetos prioritários para a implantação física do PHNM elencados e desenvolvidos

Atividade 2.2.1 - Elaborar estudos para subsidiar a concepção de roteiros interpretativos do PHNM, tendo como referência a experiência internacional em metodologias no tema, em especial em sítios do Patrimônio Mundial

Atividade 2.2.2 - Elaborar estudos com vistas ao desenvolvimento de sinalização indicativa e interpretativa do PHMN, com base em metodologia de interpretative planning e experiências internacionais em paisagens culturais.

Atividade 2.2.3 - Elaborar o diagnóstico e propor diretrizes de preservação, conservação e estabilização dos remanescentes históricos do PHNM, com base em inovaçöes tecnológicas e experiências internacionais.

Atividade 2.2.4 - Definir estruturas de apoio ao funcionamento do parque nas áreas prioritárias, conforme estabelecimento das paisagens de interesse. Atividade 2.2.5 - Elaborar estudos e desenvolver projetos de valorização dos elementos constituintes da Paisagem Cultural do PHNM, a exemplo de iluminação e acessibilidade, bem como outros voltados à implementação da sua estrutura fisica, contando-se com referências internacionais de parques históricos e paisagens culturais.

Resultado 2.3 - Programas de açōes educativas e de promoção do PHNM desenvolvidos

Atividade 2.3.1 - Conceber e testar programa de capacitação de técnicos do IPHAN para apoiar a implementação do PHNM

Atividade 2.3.2 - Conceber e testar plano de fortalecimento de capacidades de gestores municipais e comunidade para a proposição, desenvolvimento e monitoramento das açöes dos projetos associados ao PHNM, visando o desenvolvimento sustentável da região.

Atividade 2.3.3 - Conceber programa de ações educativas para guias e futuros visitantes do Parque

Atividade 2.3.4 - Conceber programa de promoção para a divulgação do PHNM.
Tabela 3: Estrutura lógica de objetivos, resultados e atividades do Projeto Missões 
A Comissão Executiva é aquela que se prevê mais presente no território, ao congregar os atores locais: o Chefe do PHNM (antigo Escritório Técnico de São Miguel das Missões), a representação Guarani, a representação do gabinete do prefeito das Prefeituras dos municípios envolvidos, do Governo do Estado e associações civis. O amplo universo de prefeituras afetadas e a preocupação de não deixar a comissão pouco operativa fez surgir a proposta da representação direta das prefeituras dos municípios dos antigos Sete Povos das Missões, enquanto que os demais municípios sejam representados pela Associação de Municípios das Missões, já existente. Das associações civis preliminarmente mapeadas e convidadas para compor a Comissão, diretamente interessadas na condução do projeto, foram apontadas a Fundação dos Municípios das Missões, a Associação dos Amigos das Missões e a Defesa Civil do Patrimônio Histórico (DEFENDER). Durante a reunião de lançamento do projeto, foi enumerada outra série de potenciais parceiros que poderão ser chamados ao longo do desenvolvimento do projeto, conforme listado na tabela 2.

A estrutura de governança permite ainda a assessoria especializada de instituições nacionais, como universidades locais, ou internacionais, particularmente o Instituto Andaluz do Patrimônio Histórico - IAPH, cuja experiência construída ao longo dos anos com seu Laboratório de Paisagem tornou-se referência importante no contexto europeu.

\section{PRIMEIRAS AÇÕES}

Após a I Reunião da Coordenação do Projeto (Comitê Gestor e Comissão Executiva, com o Grupo Assessor presente), em agosto de 2014, foi realizada a II Reunião do Comitê Gestor em outubro do mesmo ano, na qual foram discutidas questões operacionais. Nos últimos meses do ano, foi contratado o primeiro consultor para prestar apoio à Coordenação Nacional do Projeto e à Assessoria de Relações Internacionais da Presidência do IPHAN no desenvolvimento e suporte aos trabalhos. Foram realizadas também as tratativas para o estabelecimento de uma identidade visual do Projeto associada às suas premissas e objetivos.

As eleições nacionais e estaduais de 2014 e a incerteza gerada quanto à continuidade de projetos governamentais trouxeram atrasos, mas os repasses financeiros realizados ainda em 2014 asseguraram condições para o desenvolvimento do Projeto Missões ao longo 
de 2015. Este se iniciou com boas perspectivas, com a formalização da parceria com o espanhol IAPH e, em decorrência, a programação dos primeiros cursos de capacitação, considerados necessários e estratégicos para apoiar as equipes no desenvolvimento das atividades. Foi criada a marca do projeto por renomada empresa de design brasileira, buscando reforçar a ideia de encontro de culturas na região.

Criou-se ainda um Grupo de Trabalho - GT de caráter técnico, formado por representantes da Superintendência do IPHAN no Rio Grande do Sul, dos Departamentos e da Assessoria de Relações Internacionais. Este GT deverá subsidiar os termos de referência das contratações e a análise dos produtos produzidos. Encontra-se em andamento, neste primeiro semestre de 2015 , o processo de contratação da equipe de consultores para o desenvolvimento da primeira etapa do Projeto.

Em março deste ano, foi realizada a primeira atividade de cooperação com o IAPH, o Curso "Paisagem e Patrimônio Cultural - Introdução à Leitura Patrimonial da Paisagem", em Porto Alegre, direcionado à equipe do IPHAN e abordando o conceito de Paisagem Cultural e os critérios metodológicos para sua identificação e análise, de modo a subsidiar a programação dos estudos sobre a paisagem da região das Missões. O curso apresentou ainda dois estudos de caso: as paisagens da "Enseada de Bolonia" e do Centro Histórico de Sevilha, onde o IAPH desenvolveu ferramentas de apoio à gestão, entre elas a denominada "Guia da Paisagem".

\section{CONSIDERAÇÕES FINAIS}

Dado seu caráter estruturante, o Projeto Missões deverá formular uma proposta realista, pactuada e compartilhada para a gestão de um território amplo, cuja implantação dependerá da força das condições construídas, mas também, certamente, de fatores externos. Nesse tipo de enfoque, cuja perspectiva é de médio a longo prazo, diversos riscos se apresentam, como a troca de atores, a mudança de prioridades em ciclos de gestão subsequentes, a capacidade de resposta das estruturas atuais configuradas, entre outros.

Por esse motivo, alguns aspectos do Projeto adquirem grande importância, como a estratégia de comunicação interna e externa, o envolvimento de profissionais das instituições 
participantes e de atores locais de modo a atuarem como apoiadores e multiplicadores do Projeto, o fortalecimento das instâncias de governança e da rede de parceiros, a transparência nos processos e resultados e, por fim, o controle e o monitoramento do Projeto, desafios estes relevantes para assegurar uma efetiva leitura patrimonial da paisagem.

Espera-se com esta experiência trazer uma contribuição significativa para o debate e estruturação da gestão de paisagens culturais e de parques históricos no contexto brasileiro.

\section{REFERÊNCIAS BIBLIOGRÁFICAS}

ORGANIZAÇÃO DAS NAÇÕES UNIDAS PARA A EDUCAÇÃO E A CULTURA; AGÉNCIA BRASILEIRA DE COOPERAÇÃO; IPHAN. (2014). "Projeto de Cooperação Técnica Internacional - Valorização da Paisagem Cultural e do Parque Histórico Nacional das Missões Jesuíticas dos Guaranis”. Brasília. 